possible subcortical sites for emotional epilepsy are the limbic system and the region of the hypothalamus. Parts of the limbic system, notably Ammon's horn and the amygdala, lie within the temporal lobe and are frequently associated with epilepsy. But attacks of laughter or weeping may occur with midline lesions abutting the hypothalamus, ${ }^{11}$ basal ganglia, ${ }^{11}$ and third ventricle. ${ }^{12}$ Some are associated with orgasmolepsy ${ }^{11}$ and sexual precocity. ${ }^{13}$ Patients may die of laughter ${ }^{14} 15$ and Foerster and Gagel ${ }^{15}$ recounted the story of an operation under local anaesthesia where the act of swabbing the floor of the 3 rd ventricle led to outbursts of hilarity.

The pathogenesis of laughter and crying has inspired eminent neurologists ${ }^{11}{ }^{13}$ to seek to define stages in the evocation of laughter at the cortex, in the posterior hypothalamus, and in the bulbar protuberances activating faciorespiratory pathways. Ironside ${ }^{13}$ differentiated the involuntary and explosive laughter of pseudobulbar and bulbar syndromes, fits of laughter, and disorders of laughter consequent upon mental changes-as with the Witzelsucht of frontal lobe lesions (in which the patient is intensely amused at his own poor jokes). Laughter may prove a powerful trigger for cataplexy, and if unilateral ${ }^{16}$ the cataplexy may strikingly resemble epilepsy. When laughter or weeping are found with bulbar palsies, multiple sclerosis, hypothalamic disorders, or infarcts giving hemiplegia, and after prefrontal leucotomy, ${ }^{17}$ they are release phenomena. These differ from epilepsy in that the patient is usually conscious of the inappropriate paroxysm-and may indeed be disgusted by the involuntary outburst it provokes. ${ }^{18}$

1 Wilson, S A K, Fournal of Neurology and Psychopathology, 1924, 4, 299.

2 British Medical Fournal, 1975, 3, 338.

3 Sethi, P K, and Surya Rao, T, fournal of Neurology, Neurosurgery, and Psychiatry, 1976, 39, 823.

${ }^{4}$ Offen, M L, et al, fournal of Neurology, Neurosurgery, and Psychiatry, $1976,39,829$.

${ }_{5}^{5}$ Yakovlev, P I, fournal of Nervous and Mental Disease, 1948, 107, 313.

${ }^{6}$ Gumpert, J, Hansotia, P, and Upton, A, fournal of Neurology, Neurosurgery, and Psychiatry, 1970, 33, 479.

${ }^{7}$ Dostoyevsky, F M, The Idiot, 1869 cited by Lennox, W G, and Lennox, $\mathrm{M} \mathrm{A}$, in Epilepsy and Related Disorders, vol 1, p 279. Boston, Little, Brown and Company, 1960.

8 Williams, D, Brain, 1968, 91, 639.

9 Stearns, F R, Laughing, p 27. Springfield, Thomas, 1972

10 Roger, J, et al, Electroencephalography and Clinical Neurophysiology, 1967, 22, 279.

${ }^{11}$ Martin, J P, Brain, 1950, 73, 453

12 Bailey, P, Intracranial Tumours, 2nd edn, p 134. Springfield, Thomas, 1948.

${ }^{13}$ Ironside, R, Brain, 1956, 79, 589

${ }_{14}$ Anderson, C, Fournal Belge de Neurologie et de Psychiatrie, 1936, 36, 323

15 Foerster, O, and Gagel, O, Zentralblatt für die Gesamte Neurologie und Psychiatrie, 1932, 138, 1.

${ }^{16}$ Lascelles, R G, Mohr, P D, and Peart, I, fournal of Neurology, Neurosurgery, and Psychiatry, 1976, 39, 1023.

17 Kramer, H C, fournal of Nervous and Mental Disease, 1954, 119, 517

18 Swash, M, Fournal of Neurology, Neurosurgery, and Psychiatry, 1972, 35, 108.

\section{"While the balance of his mind was disturbed"}

Little attention has been paid to the emotional impact of suicide inquests on the families concerned-and in particular on the husband or wife of the deceased. Barraclough and Shepherd, who recently studied the subject, ${ }^{1}$ found that despite the courtesy and kindness of the coroner in most cases the inquest inevitably aggravated the distress resulting from bereavement by suicide. As they point out, it is now five years since the Brodrick Report ${ }^{2}$ recommended that the coroner should have the discretion to dispense with inquests except for suspected homicides, unidentified bodies, and the deaths of those deprived of their liberty. The report is still on the shelf. Apart from the inquest itself press accounts may be a further source of distress; but here Barraclough and Shepherd disagreed with the report, which recommended no restriction on the reporting of suicide cases even if no inquest was held.

Certainly in most suicides the intention of the deceased and the circumstances of death are so clear-cut as to render any kind of publicly held inquest unnecessary-as indeed is apparent in Denmark, where a much less legalistic procedure is considered satisfactory. While coroners are mostly kind and the police usually helpful, events may sometimes take a remarkable turn. Thus, in one recent case (not one reported by Barraclough and Shepherd) an elderly man suffering from Parkinsonism and a mild degree of depression went with a party of other patients for a walk in a nearby park in the charge of a competent nurse. Having shepherded her group to the bus stop, the nurse warned them in due course that the bus was approaching. Quite suddenly and unexpectedly the patient stepped in front of the bus before it had completely stopped. Though most of the onlookers thought that the cause was probably the patient's having misunderstood what the nurse had said, because the death was due to a road accident it was necessary for the coroner to sit with a jury. Even after retiring twice the jury found it impossible to reach unanimous agreement, so that after some shifts in opinion the coroner finally accepted a majority verdict of six in favour of suicide and two against. The jury's inability to agree unanimously caused some degree of distress both to the patient's relatives and to the charge-nurse, who, although in no way to blame for what had occurred, none the less felt much concerned. Perhaps if the coroner had been able to sit without a jury he might have found himself in a position to give an open verdict, but in the circumstances this was hardly possible. There might also have been grounds for the patient's relatives to have exercised their right of appeal, but (as Barraclough and Shepherd state) relatives rarely know they have this right and are seldom told about it by the coroner.

There is yet another possible disadvantage to the public inquest system: it may distort the accuracy of the suicide statistics because some coroners tend to bring in a verdict of accidental death whenever there is any doubt about the deceased's actual intention, presumably to spare the relatives' feelings. Thus it sometimes happens that those who commit suicide but who do not die until a few days after the event may admit their intent to someone or other in the interim period. This, however, may not come to light at the inquest. Where there is no public inquiry distortion of the truth is possibly less likely. Thus the Danes, who have one of the highest suicide rates in Europe and are sensitive about it, maintain that this is because their system, which is based on having no inquest, gives a truer account of the matter.

Kessel, ${ }^{3}$ who devised a project to measure the extent to which international comparisons of suicide rates were reliable, came to the conclusion that because more rigorous standards of legal proof were required in England this possibly could influence the verdict. But protection of the feelings of the bereaved should surely be the prime consideration. If a more humane system led to verdicts becoming more accurate that could be regarded as a statistical bonus.

${ }^{1}$ Barraclough, B M, and Shepherd, D M, British fournal of Psychiatry, 1976, 129, 109.

2 Home Office, Report on Death Certification and Coroners, Cmnd 4810 London, HMSO, 1971.

${ }^{3}$ Suicide and Attempted Suicide, ed Eileen $\mathrm{M}$ Brooke and $\mathrm{M}$ Atkinson. Geneva, World Health Organisation, 1974. 